\title{
Penguatan Pendidikan Karakter Berbasis Humanistik Melalui Kearifan Lokal dan Nilai Pendidikan Islam Pada Anak Panti Asuhan
}

\author{
Muhamad Taufik Bintang Kejora ${ }^{1}$, Achmad Junaedi Sittika ${ }^{2}$, Ahmad \\ Syahid $^{3}$ \\ ${ }^{123}$ Fakultas Agama Islam Universitas Singaperbangsa Karawang \\ Email : kejora.smart@gmail.com
}

Article History:

Received: Desember 2020

Revised: Mei 2021

Accepted: Juni 2021

Available online: Juni 2021

\section{Kata Kunci: \\ Pendidikan Karakter, Humanistik,Kearifan Lokal, Pendidikan Islam}

\begin{abstract}
Abstrak:
Kegiatan pengabdian ini bertujuan menginternalisasikan nilai-nilai penguatan pendidikan karakter secara humanistik pada anak panti asuhan Al-Hidayah Purwakarta. Pembentukan karakter diimplementasikan melalui kearifan lokal sunda dan penanaman nilai-nilai pendidikan Islam. Proses pengabdian dilaksanakan secara inovatif melalui kegiatan sosialisasi, kegiatan keagamaan, penyuluhan, pembiasaan, pembelajaran, pemotivasian, games dan pembudayaan. Hasil kegiatan menunjukkan pembinaan karakter secara humanistik menumbuhkan rasa percaya diri, kreativitas, rasa saling menyayangi dan saling peduli. Anak belajar dengan riang, aktif, kreatif dan efektif. Melalui penanaman nilai-nilai pendidikan Islam, membantu anak secara mandiri untuk mengembangkan karakter religius, integritas, dan kemandirian. Melalui kearifan lokal Sunda, menguatkan karakter nasionalis, integritas, gotong royong dan kemandiriaan serta menjadi pribadi cageur (sehat), bageur (baik), bener (benar), singer (mawas diri), dan pinter (cerdas sebagaimana tata nilai masyarakat Sunda.
\end{abstract}




\section{Pendahuluan}

Panti Asuhan Anak Al-Hidayah merupakan lembaga sosial dan pendidikan Islam yang berada di Kabupaten Purwakarta. Panti asuhan AlHidayah menaungi 37 anak panti dengan beragam latar belakang sosial dan ekonomi seperti anak yatim-piatu, anak keluarga tidak mampu, anak terlantar dan anak korban kekerasan keluarga/orangtua. Berdasarkan data, terdapat 2 orang anak usia SMA, 8 anak usia SMP, 25 anak usia SD, dan 2 anak usia dini. Anak-anak panti Al-Hidayah melaksanakan kegiatan pendidikan formal di sekolah-sekolah negeri di kabupaten Purwakarta, mulai untuk jenjang SD sampai SMA.

Pemerintah kabupeten Purwakarta melakukan perubahan sistem pendidikan sekolah dasar dan menengah dengan memunculkan kesadaran akan dimensi agama dan kebudayaan dengan memunculkan kearifan lokal masyarakat Sunda (Cece, 2019). Hal ini dituangkan dalam Peraturan Bupati Nomor 69 Tahun 2015 tentang Pendidikan Berkarakter (Aziz, 2018). Pemerintah kabupaten Purwakarta membangun karakter melalui program Tujuh Poe Atikan Purwakarta Istimewa; atau program tujuh hari Pendidikan Purwakarta Istimewa (Hude, D., Febrianti, N.A., 2019). Kebijakan pendidikan karakter ini bertujuan membentuk manusia purwakarta berkarakter dengan mengedepankan budaya Sunda dan nilai-nilai pendidikan Islam yang berlaku di tengah masyarakat (Latiep, 2014).

Program ini juga bertujuan membentuk generasi muda secara humanistik sesuai dengan tata nilai masyarakat Sunda di Jawa-Barat yaitu: cageur, bageur, bener, pinter jeung singer (Budiyanti dkk., 2020). Dengan adanya kebijakan tersebut, maka keberlangsungan pendidikan di kabupaten Purwakarta berdasar pada program "Tujuh Poe Atikan Purwakarta Istimewa" harus diintegrasikan dalam berbagai kegiatan pendidikan dan pengajaran dengan bernafaskan kearifan lokal dan nilai-nilai pendidikan Islam (Suciyanti $\&$ Nita, 2019). Nilai pendidikan Islam yang diimplemenatsikan di diantaranya merupakan nilai-nilai karakter yang terkandung dalam Al-Qur'an Surat Lukman ayat 12 - 19 yaitu bersyukur, tauhid, ihsan, sabar, berbakti pada orangtua, tidak angkuh dan sombong, sederhana, dan tolong-menolong (Fajar, 
2019). Nilai-nilai tersebut yang kemudian diinternalisasikan melalui kegiatan pembelajaran dan aktivitas keseharian di sekolah maupun di lingkungan masyarakat (N. Fitri \& Idris, 2019). Dengan demikian generasi muda diharapkan tidak sekedar piawai dalam menjawab soal ujian namun juga berdaya menjawab persoalan hidup yang dihadapi, memiliki sikap religius, nasionalisme, kejujuran, kemandirian dan sikap gotong royong (A. . Fitri, 2020). Program ini sejalan dengan nilai-nilai penguatan pendidikan karakter (PPK) sebagaimana tertuang dalam Peraturan Presiden Republik Indonesia Nomor 87 Tahun 2017 Tentang Penguatan Pendidikan Karakter (Taufik, 2020: 79). Nilai-nilai PPK merupakan nilai utama yang perlu dikembangkan dan menjadi prioritas dalam revolusi mental yang mencakup 5 nilai-nilai karakter yaitu religius, nasionalis, integritas, mandiri dan gotong royong. (Atik Maisaro, Bambang Budi Wiyono, 2018).

PPK dalam pelaksanaannya memerlukan keterlibatan berbagai pihak diantaranya adalah peran serta masyarakat dan keluarga. Panti asuhan AlHidayah dibawah naungan Yayasan Pendidikan Islam Al-Hidayah, menjadi lembaga yang cukup strategis dalam melakukan upaya transfer of knowledge dan transver of value melalui pembinaan dan penguatan karakter kepada warga panti (anak-anak panti). Keberhasilan proses dan tujuan pendidikan karakter tidak akan terwujud tanpa dukungan masyarakat (Taufan \& Sapriya, 2018). Anak-anak panti asuhan merupakan generasi penerus bangsa yang juga memerlukan penguatan dan pembinaan karakter sehingga tumbuh menjadi generasi tangguh, berkarakter dan berakhlakul karimah (Utomo, 2017). Dengan kata lain, baik-buruknya karakter anak-anak panti akan menjadi tanggung jawab bersama dalam hal ini adalah warga masyarakat, pemerintah dan pengasuh panti.

Dalam menanamkan nilai-nilai kepada anak diperlukan pendekatan humanistik agar anak secara mandiri mampu menggali keterampilan dan potensi dirinya (Firdaus, 2017). Proses pendidikan tidak boleh membelenggu siswa. Pendidikan harus mampu memfasilitasi siswa secara transformatif dan demokratis mencapai aktualisasi diri mengenal dirinya, mengenal Tuhan-nya, mengenal lingkungan,mengenal budayanya dan mengenal alamnya (Perbawasari dkk., 2020). Pendidikan harus mampu menggali dan 
mengembangkan potensi peserta didik yang bermanfaat bagi dirinya untuk menjawab tantangan kehidupan di masa mendatang (Baharrudin \& Makin, 2011). Nilai-nilai yang diinternalisasikan kepada anak di sesuaikan dengan tata nilai yang berlaku di masyarakat setermpat dengan mengedepankan empat pilar pendidikan yakni: (1) learning to know, (2) learning to do (3) learning to be, dan (4) learning to live together (Usman, 2017).

\section{Tujuan dan Manfaat}

Tujuan kegiatan pengabdian kepada masyaarakat (PKM) antara lain: 1) menanamkan nilai-nilai penguatan pendidikan karakter (religius, nasionlais, integritas, mandiri dan gotong-royong) pada anak panti asuhan AlHidayah Purwakarta; 2) menanamkan kebiasan hidup yang sesuai dengan nilai-nilai ajaran Islam; dan 3) melestarikan budaya bangsa dan kearian lokal sebagai nilai-nilai penguatan karakter.

Bagi dosen, kegiatan PKM ini tentunya memberi manfaat positif bagi pengembangan kompetensi tridarma perguruan tinggi bidang pengabdian masyarakat. Bagi lembaga panti asuhan Al-Hidayah, memberi referensi terkait kegiatan dan pembiasaan yang dapat diimplementasikan guna mengembangkan karakter anak panti. Adapun bagi santri atau anak panti, memperoleh pengalaman belajar yang dapat menambah wawasan dan pengembangan sikap, ketauhida, karakter cinta budaya, dan motivasi untuk terus belajar.

\section{Metode}

Kegiatan ini merupakan bagian dari tridarma perguruan tinggi dosen Universitas Singaperbangsa Karawang. Kegiatan dilaksanakan selama 2 bulan yaitu pada bulan Oktober - November 2020. Metode pengabdian dilakukan melalui sosialisasi, ceramah keagamaan, penyuluhan, pembiasaan, pembelajaran, pemotivasian, games dan pembudayaan. Adapun kelompok sasaran kegiatan pengabdian kepada masyarakat ini adalah anak-anak warga panti asuhan Al-Hidayah Purwakarta. 


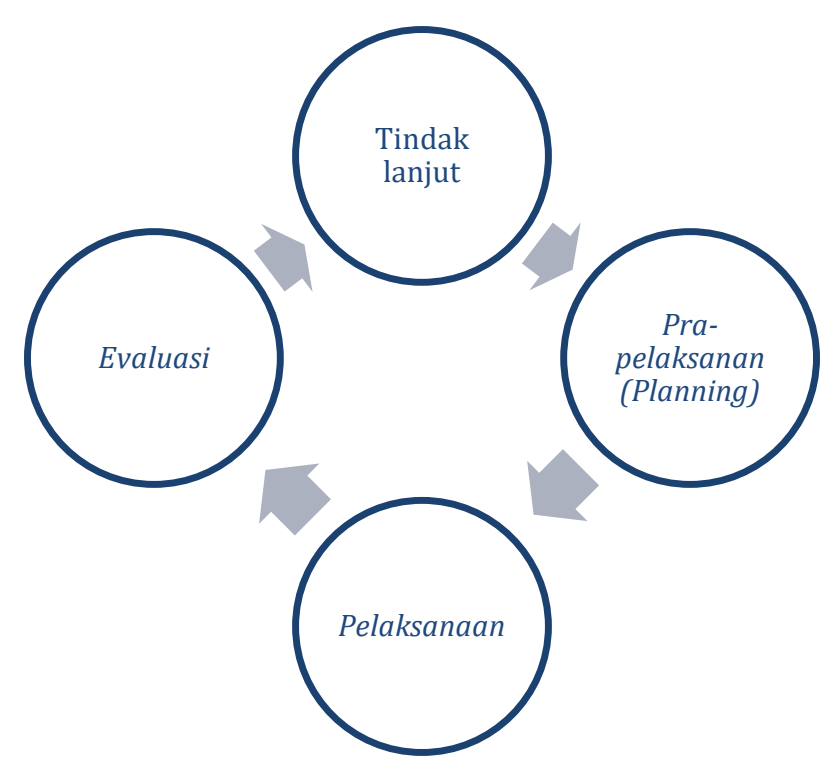

Gambar 1. Diagram Alur Kegiatan PKM

\section{Hasil}

Kegiatan PKM dilaksanakan dalam 3 tahapan yaitu tahap pra pelaksanaan, tahap pelaksanaan, dan tahap pasca pelaksanaan kegiatan.

\section{Tahap Pra-Pelaksanaan}

Pada tahap pra pelaksanaan dilakukan perencanaan kegiatan diantaranya menentukan lembaga mitra PKM, melakukan identifikasi masalah dan mengklarifikasi potensi yang ada pada kelompok sasaran, serta menentukan metode dan jenis kegiatan yang sesuai dengan kebutuhan sasaran/mitra. Identifikasi masalah dan klarifikasi potensi mitra dilakukan melalui wawancara yang melibatkan pihak pengelola yayasan, pengasuh panti, pengajar, tokoh masyarakat, aparatur pemerintahan desa, dan warga panti (anak-anak panti). Hasilnya menunjukkan masih kurangnya pengetahuan, pengenalan, pembiasaan dan pembudayaan nilai-nilai budaya sunda dan peningkatan softskill keagamaan bagi anak panti.

Berdasarkan hasil identifikasi masalah dan klarifikasi potensi, dilakukan dialog dengan pihak pengelola panti mengenai alternatif solusi yang 
diperlukan. Kemudian dituangkan dalam perencanaan dan rancangan kegiatan yang akan dilaksanakan. Perencanaan kegiatan dituangkan dalam bentuk agenda kegiatan, setelah itu Dosen bersama pihak mitra mempersiapkan sarana-prasarana, pendanaan, dan sumber daya menusia yang diperlukan termasuk melakukan pengorganisasian.

2. Tahap Pelaksanaan

Penguatan Pendidikan karakter yang diterapkan pada anak-anak panti asuhan Al-hidayah dilaksanakan melalui dua kegiatan utama yaitu kegiatan keagamaan dan kearifan lokal Sunda.

a. Penguatan karakter melalui aktivitas keagamaan

Aktivitas penguatan karakter melalui kegiatan keagamaan diimplementasikan melalui dua metode kegiatan yaitu langsung (direct) dan tidak langsung (indirect). Kegiatan langsung (direct) adalah kegiatan penguatan karakter dimana tim dosen terlibat langsung dalam kegiatan. Tim dosen turun langsung berinteraksi dengan anak panti dalam melakukan pembinaan melalui beragam program kegiatan keagamaan. Diantaranya adalah: 1) seminar ESQ berjudul "Kehidupan Bahagia di Atas Jalan Tuhan", 2) seminar pembentukan karakter bertajuk "Muhammad is The Best Idol", dan 3) seminar kepemimpinan bertajuk "Be My Self; Aku Bangga Menjadi Diriku”.

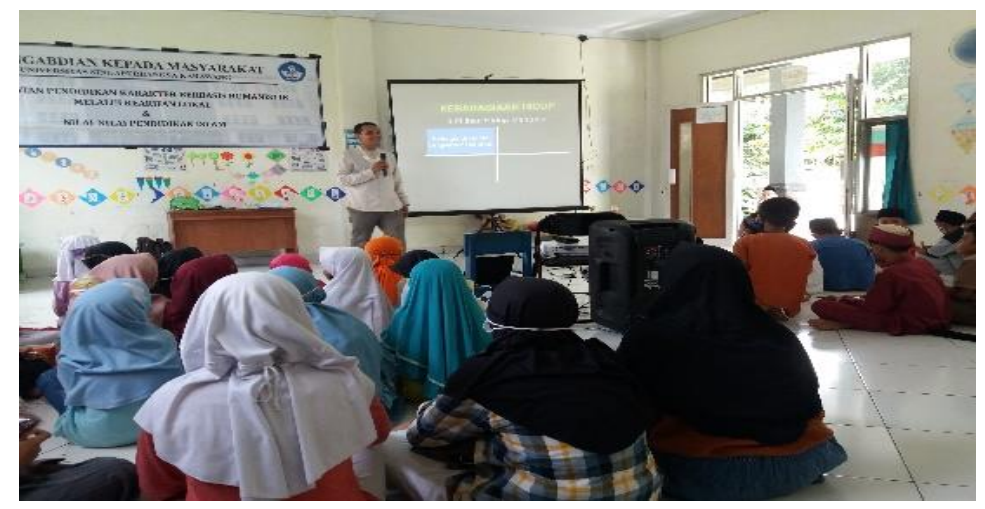

Gambar 2. Seminar Kepemimpinan 
Adapun kegiatan tidak langsung (indirect) adalah kegiatan penguatan karakter dimana tim dosen tidak secara langsung turun berinteraksi dengan anak panti, melainkan dibantu oleh partisipan atau relawan. Ini biasanya dilaksanakan setiap hari sebagai rutinitas pembelajaran dan kegiatan harian di panti. Kegiatan indirect yang dilaksanakan diantaranya adalah: a) pengajaran baca tulis Al-Qur'an (BTQ), b) hafalan juz 30, c) pengamalan puasa sunnah Senin-Kamis, d) shalat dhuha bersama, e) shirah nabawiyah, f) ilmu nahwu shorof, g) pembelajaran praktik shalat, h) pengajaran ilmu fiqh, i) pengajian kitab ta'lim muta'alim, j) merapikan sajadah, mukena dan posisi sandal di masjid, dan k) birul walidain (berbakti pada kedua orangtua).

2) Penguatan karakter melalui kearifan lokal Sunda

Pada kegiatan penguatan karakter yang dilaksanakan secara langsung (direct), tim dosen turun langsung kepada anak panti melakukan beragam kegiatan dan pembinaan karakter. Tim dosen melakukan penanaman karakter melalui pengenalan permainan tradisional seperti ucing sandal, egrang, congklak, galah santang, somlah dan permainan gatrik. Melalui permainan tradisional, anak dilatih melatih ketangkasan, semangat kebersamaan, kejujuran dan sportifitas. Penanaman karakter dilaksanakan melalui cara yang tidak membebani anak. Anak mengalami pengalaman belajar melalui pembelajaran aktif, kreatif, dan menyenangkan.

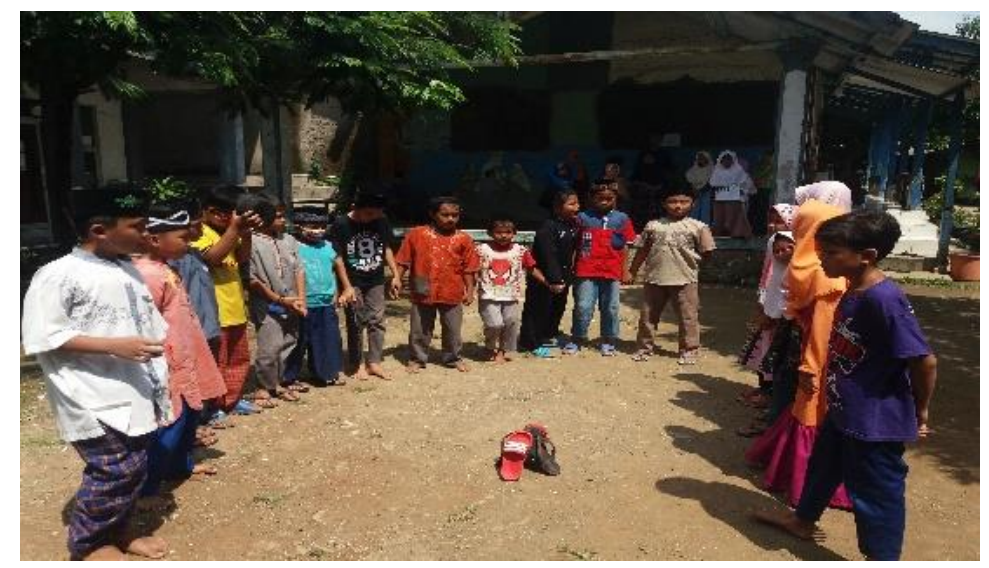

Gambar 3. Permainan Tradisional Sunda (Ucing Sandal) 
Selain melalui permainan tradisional, pembinaan karakter secara langsung (direct) dilaksanakan melalui kegiatan kesenian. Ini melatih sense of beauty pada anak. Kegiatan seni yang dilaksanakan antara lain mengajarkan anak lagu "Mars Penguatan Pendidikan Karakter" dan lagu daerah sunda "Teu Honcewang". Kegiatan lain adalah berupa penguatan karakter melalui cerita rakyat Jawa-Barat. Pada kegiatan ini anak dibagi menjadi beberapa kelompok. Lalu masing-masing kelompok diberikan teks cerita rakyat dan membacakannya serta membuat simpulan hikmah dalam cerita rakyat tersebut. Cerita rakyat yang diperkenalkan kepada anak adalah lutung kasarung, Sangkuriang, Si Kabayan, Sakadang kuya jeung sakadang monyet, dan Prabu Siliwangi. Nampak anak belajar penuh rasa riang, gembira dan penuh canda tawa. Anak mampu mengekspresikan kemampuannya masingmasing dengan membacakan cerita sesuai kreatifitas dan imajinasi. Melalui cerita rakyat ini, anak dikenalkan pada literasi budaya sunda dan menganalisa nilai-nilai karakter kesundaan yang terdapat pada cerita rakyat.

Penguatan karakter yang dilaksanakan secara tidak langsung (indirect), kegiatan dibantu dan diisi oleh partisipan atau relawan. Anak diajarkan melantunkan beberapa pupuh dan sajak berbahasa Sunda. Anak dianjurkan membawa bekal makanan sendiri yang berbahan dasar umbiumbian seperti kacang rebus, singkong, jagung dan ubi. Tujuannya adalah agar anak mengenal dan melestarikan makanan khas daerah di Jawa-Barat (Sunda). Anak dibimbing berbicara bahasa Sunda Loma yaitu bahasa Sunda yang santun dan penuh tata krama seperti membiasakan kalimat punten (permisi/tolong), hapunten (maaf), dan hatur nuhun (terima kasih). Melalui kearifan lokal, anak diperkenalkan pula dengan falsafah silih asah, silih asih dan silih asuh.

\section{Tahap Pasca Pelaksanaan}

Pada tahap pasca pelaksanaan, dilanjutkan dengan membangun komitmen bersama dalam melanjutkan penguatan karakter terhadap anakanak panti. Metode yang digunakan berupa sharing, diskusi, dan pendampingan intensif secara kontinu dan berkelanjutan. 


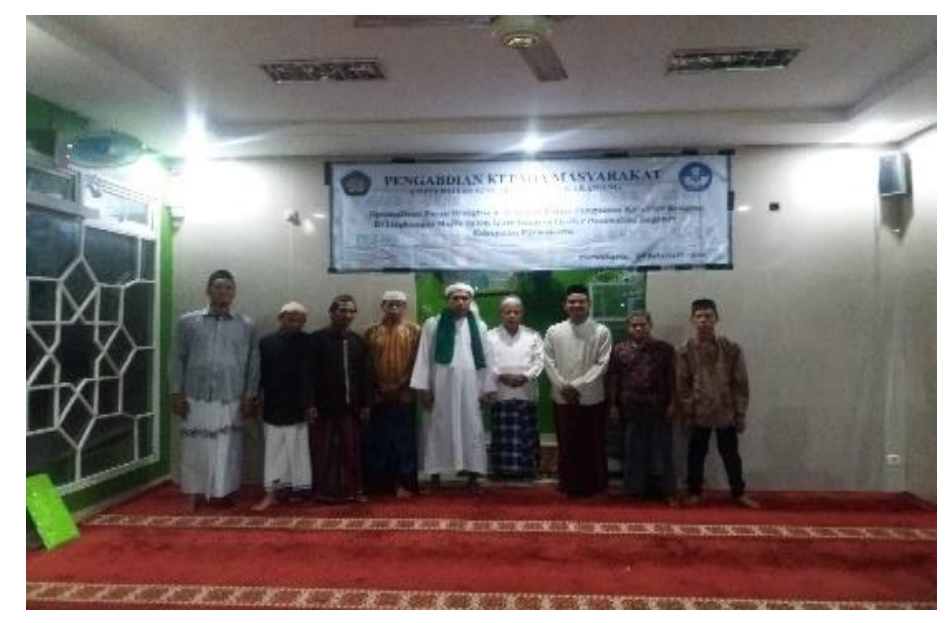

Gambar 4. Komitmen Berkelanjutan

Komitmen ini diealisasikan dengan menjadwalkan kajian rutin/pengajian yang diadakan setiap hari Jum'at akan diisi sebulan sekali oleh Muhamad Taufik BK, S.Pd.I., M.Pd., selaku Dosen Universitas Singaperbangsa yang juga pemateri dalam kegiatan PKM.

\section{Diskusi}

Penguatan karakter dilakukan melalui aktivitas keagamaan dan penanaman nilai filosofi kesundaan. Penanaman karakter melalui aktivitas keagamaan diantaranya dilaksanakan dengan pengajaran baca tulis Al-Qur'an (BTQ), hafalan juz 30, pengamalan puasa sunnah Senin-Kamis, shalat dhuha bersama, merapikan sajadah, mukena dan posisi sandal di masjid. Tujuanya adalah mampu membentuk karakter religius, integritas, dan kemandirian pada kepsibadian anak panti. Hasilnya pun menunjukan adanya peningkatan kemampuan membaca Al-Qur'an, hafalan surat pada juz 30, meningkatnya jumlah anak yang melaksanakan puasa sunnah dan masjid yang tertata dengan baik saat sebelum dan sesudah aktivitas keagamaan.

Adapun nilai-nilai filosofi kesundaan yang hendak dibentuk pada kepribadian anak adalah bageur (baik), bener (benar), singer (mawas diri). Ini diimplementasikan melalu beragam kegiatan peningkatan skill keagamaan. Penguatan karakter melalui kearifan lokal Sunda membentuk karakter nasionalis, integritas, gotong royong dan kemandirian. Budaya sunda dikenal 
kaya dengan falsafah dan nilai-nilai kehidupan yang dekat dengan aktivitas fisik dan natural. Adapun nilai-nilai filosofi kesundaan yang hendak dibentuk pada kepribadian anak adalah cageur (sehat), bageur (baik), bener (benar), singer (mawas diri), dan pinter (cerdas).

Pembinaan karakter melalui kegiatan seni tradisional seperti membaca cerita tradisional Sunda dan melantunkan lagu tradisional bertujuan menanamkan sikap nasionalisme dan melestarikan budaya bangsa. Hasilnya menunjukkan sebagian besar anak mampu meningkatkan rasa percaya diri, keterampilan berkomunikasi dan kemampuan sosial emosi yang baik.

Melalui permainan tradisional melatih ketangkasan anak, semangat kebersamaan, kejujuran dan sportifitas. Indonesia sebagai negara yang kaya akan budaya, setiap daerah memiliki permainan tradisional sebagai warisan leluhur bangsa. Permainan tersebut mengandung nilai-nilai edukasi yang dapat ditanamkan pada anak. Demikian pula permainan tradisional Sunda seperti ucing sandal, egrang, congklak, galah santang, somlah dan permainan gatrik memiliki nilai falsafah kehidupan masyarakat Jawa-Barat. Melalui permainan tradisional, anak panti dikenalkan dan diarahkan pada nilai-nilai falsafah budaya Sunda yang sudah dikenal baik secara nasional maupun internasional yaitu sebagai berikut:

a) Silih asah: kita harus saling membelajarkan, harus saling mengisi dengan ilmu pengetahuan, sehingga kita semua menjadi manusia yang memiliki pengetahuan yang luas

b) Silih asih : Kita hidup dengan sesama harus saling mengasihi. Kita harus menolong orang yang membutuhkan pertolongan kita.

c) Silih asuh : memberikan nilai yang positif, memiliki cita-cita masyarakat bangsa yang teratur baik, dimana setiap orang mengenal tempat atau posisinya masing-masing dan turut saling menjaga agar menjadi satu kesatuan yang harmoni.

Hasil pengamatan mengenai aktivitas permainan tradisional, menunjukkan terjadinya peningkatan sikap anak dalam interaksi antar sebaya, berkembangnya perilaku prososial, sikap integritas dan saling tolongmenolong. 
Selama program penguatan karakter berbasis humanistik ini diselenggarakan, secara afektif anak menunjukkan perkembangan yang cukup signifikan pada 5 aspek PPK religius, nasionalis, integritas, mandiri dan gotong royong. Anak-anak menunjukkan perilaku silih asah, silih asih, dan silih asuh dalam aktivitas keseharian di panti.

Setelah serangkaian program penguatan dilaksanakan, dilakukan komitmen bersama antara pihak dosen dengan pihak Yayasan Panti Asuhan Al-Hidayah. Hal ini merupakan sebuah kesempatan besar membangun jejaring sosial bagi dosen Universitas Singaperbaangsa Karawang untuk istiqomah melaksanakan Tridharma Perguruan Tinggi melalui pemberdayaan masyarakat untuk berpartisipasi aktif membangun pendidikan karakter maupun program-program pendidikan lainnya melalui pemberdayaan anakanak panti asuhan. Mengingat panti asuhan merupakan pusat sumber belajar bagi masyarakat khususnya anak-anak panti. Selain itu sebagai lembaga pendidikan non formal maka sepantasnya pula panti asuhan dan warga panti memperoleh perhatian berupa pengembangan dan pemberdayaan yang dapat meningkatkan hardskill dan softskill sebagai bekal menghadapai kehidupan di masa mendatang.

\section{Kesimpulan}

Berdasarkan hasil kegiatan pengabdian pada masyarakat dapat disimpulkan beberapa hal sebagai berikut:

a. Penguatan pendidikan karakter berbasis humanistik pada anak panti menumbuhkan rasa percaya diri, kreativitas, rasa saling menyayangi dan saling peduli pada diri anak. Anak belajar dengan riang, aktif, kreatif dan efektif. Melalui penanaman nilai-nilai pendidikan Islam, membantu anak secara mandiri untuk mengembangkan karakter religius, integritas, dan kemandirian. Melalui kearifan lokal, menguatkan karakter nasionalis, integritas, gotong royong dan kemandirian.

b. Anak-anak panti mampu mengamalkan pembiasaan yang diimplemtasikan dalam kehidupan sehari-hari seperti pengajaran baca tulis Al-Qur'an (BTQ), hafalan juz 30, pengamalan puasa 
sunnah Senin-Kamis, shalat dhuha bersama, merapikan sajadah, mukena dan posisi sandal di masjid.

c. Kegiatan PKM penguatan pendidikan karakter pada anak panti asuhan secara efektif mampu menanamkan nilai-nilai kearifan lokal kesundaan, melestarikan budaya bangsa, dan menumbuhkan rasa nasionalisme yang tinggi pada generasi bangsa.

\section{Pengakuan/Acknowledgements}

Kami mengucapkan terima kasih kepada Rektor, Ketua LPPM, Dekan Fakultas Agama Islam dan seluruh civitas akademika Universitas Singaperbangsa yang telah memberikan motivasi dan dukungan baik moril, materil maupun spiritual. Demikian pula kepada pihak pemerintah kabupaten Purwakarta dalam hal ini kepala kelurahan Nagri Tengah Purwakarta dan segenap pengurus dan staff Yayasan Pendidikan Islam Al-Hidayah Purwakarta yang telah memberi perizinan dan bantuan sehingga pengabdian kepada masyarakat khususnya kepada anak-anak panti asuhan Al-Hidayah dapat terselenggara dengan baik.

\section{Daftar Referensi}

Atik Maisaro, Bambang Budi Wiyono, I. A. (2018). Manajement Program Penguatan Pendidikan Karakter di Sekolah Dasar. Jurnal Adminitrasi Dan Manajemen Pendidikan, 1(3), 302-312.

Aziz, H. (2018). Analisis Kebijakan Pemerintah Purwakarta tentang Pendidikan Karakter Berbasis Kearifan Lokal di Kabupaten Purwakarta [Analysis of Purwakarta Government Policy on Character Education Based on Local Wisdom in Purwakarta Regency]. Golden Age: Jurnal Pendidikan Anak Usia Dini, 2(1), 11-18. https://doi.org/10.29313/ga.v2i1.4167

Budiyanti, N., Aziz, As. A., \& Palah. (2020). the Formulation of the Goal of Insan Kamil As a Basis for the. IJECA (International Journal of Education and Curriculum Application), 3(2), 1-10.

Cece. (2019). Penguatan Pendidikan Karakter Melalui Kearifan Lokal Berbasis Al-Qur'an (Implementasi di SMAN Kabupaten Purwakarta) [Strengthening Character Education through Al-Qur'an-Based Local Wisdom (Implemented at SMAN Purwakarta Regency)]. Deepublish.

Fajar, I. (2019). Pendidikan Karakter Dalam Al-Qur'an. Ar-Risalah: Media 
Keislaman, Pendidikan Dan Hukum Islam, 17(2), 144. https://doi.org/10.29062/arrisalah.v17i2.270

Firdaus. (2017). Membentuk Pribadi Berakhlakul Karimah Secara Psikologis. Jurnal Al-Dzikra, 11(1), 55-88. http://ejournal.radenintan.ac.id/index.php/al-dzikra/article/view/1813

Fitri, A. . (2020). Pendidikan Karakter Berbasis Nilai \& Etika di Sekolah [Values \& Ethics Based Character Education in Schools]. Ar-Rurzz.

Fitri, N., \& Idris, M. (2019). Nilai Pendidikan Islam dalam Qur'an Surah Luqman Ayat 1-19: Tinjauan Kognitif, Afektif, dan Psikomotorik (The Value of Islamic Education in the Qur'an Surah Luqman Verses 1-19: Cognitive, Affective, and Psychomotor Reviews). Al-Musannif, 1(1), 3246. https://doi.org/https://doi.org/10.5281/zenodo.2667704

Hude, D., Febrianti, N.A., \& C. (2019). Alim | Journal of Islamic Educatioan. Alim Journal of Islamic, I(2), 389-400.

Latiep, A. . (2014). No Title. Harapan Pendidikan Nasional Pada Jenjang

Pendidikan Dasar Dalam Pembangunan Karakter Budaya Dan Daya Saing Bangsa [Expectations of National Education at Basic Education Level in the Development of Cultural Character and National Competitiveness]., 440-448.

Perbawasari, S., Dida, S., Nugraha, A., \& Adi, A. (2020). Communication of Character Education through Special Purwakarta 7 Days of Education (7 Poe Atikan) (Qualitative Descriptive Study on Character Education in Purwakarta Regency). https://doi.org/10.4108/eai.5-11-2019.2292522

Suciyanti, Y., \& Nita, A. M. (2019). Madrosatuna: Jurnal Pendidikan Guru Madrasah Ibtidaiyah Madrosatuna : Jurnal Pendidikan Guru Madrasah Ibtidaiyah. 2(22), 1-13.

Taufan \& Sapriya. (2018). Pelembagaan Karakter Toleransi Siswa Melalui Program. Jurnal Pancasila Dan Kewarganegaraan.

Usman, A. H. (2017). Humanism In Islamic Education: Humanism: Historical Perspectives The term " humanism " has a complex history and meaning . "Humanism " as The humanist movement evolved and became the forerunner of the In the early blooming of humanism in Europe , human. Ijaps, 13(1), 95-113.

Utomo, S. T. dan A. S. (2017). Internalisasi Nilai-Nilai Akhlaqul. 11(1), 5568. 